\title{
Initial stages of ontogenesis of Althaea officinalis L. in the "Kuzbass Botanical Garden"
}

\author{
Oksana Vronskaya ${ }^{1, *}$, and Vera Cheryomushkina ${ }^{2}$ \\ 1 The Federal Research Center of Coal and Coal Chemistry of Siberian Branch of the Russian \\ Academy of Sciences, 650065, 10 Leningradskiy avenu, Kemerovo,Russia \\ ${ }^{2}$ Central Siberian Botanical Garden SB RAS, 630090, 101 st. Zolotodolinskaya, Novosibirsk, Russia.
}

\begin{abstract}
The work was carried out on the grounds of the Kuzbass Botanical Garden. The study material is a perennial, rod-rooted herbaceous plant known as Althaea officinalis L. Included in the Red Book of the Kemerovo Region with status 2 - declining. It has been found that during the first year of life, individuals go through 5 ontogenetic stages: seedling, juvenile, immature, virginile and young generative. The latent, pregenerative and generative periods of $\mathrm{A}$. officinalis are characterised in detail. The forming of the caudex and the growth of the primary semirosette monocarpic shoot is described.
\end{abstract}

\section{Introduction}

The genus Althaea L. has 25 species [1]. There are 8 species found in Russia, but only two of them, Althaea officinalis L. and Althaea armeniaca Ten, have medicinal value [2, 3]. Leaves, flowers and roots are used as medicinal raw materials [4, 5].

A. officinalis has a Eurasian range type. In Siberia, it is distributed from the Tyumen Region and Altai Krai in the west to the Republic of Khakassia in the east [6] (Fig. 1).

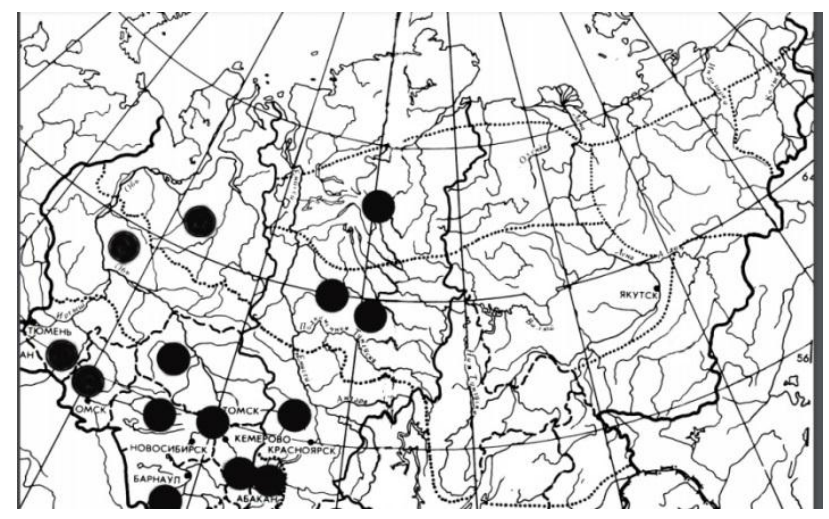

\footnotetext{
*Corresponding author: oksana_vronski@mail.ru
} 
Fig. 1. Range of Althaea officinalis in Siberia.

In the Kemerovo Region, it is found in the Leninsk-Kuznetskiy District: vicinity of Krasnaya Gorka (Kamyshnaya River valley), Novoilyinsky (Inya River valley), Chkalovsky (Casma River valley); Promyshlennovsky District: vicinity of Pushkino village and included in the Red Book of the Kemerovo Region with status $2-\operatorname{declining~[6].~} A$. officinalis grows in damp meadows, among shrubs, on the banks of rivers, the shores of lakes and marshes. It tolerates salinity well, occurring in saline, solonetzic meadows. Populations exposed to grazing, recreation and late haying are characterised by a depressed state. The uncontrolled collection of underground organs for medicinal purposes leads to a decline in the wild species [6]. To create preservation measures for A. officinalis, a study of the species' life form and ontogeny is required.

A. officinalis is a perennial, tap root herbaceous plant, up to $1.5-2$ metres high. The ontogeny of $A$. officinalis has been studied, mainly in the European part of Russia [7]. There is no information on the development of this species in Siberia.

The aim is to study the initial stages of $A$. officinalis ontogenesis under the conditions of an introduction experiment in the Kuzbass Botanical Garden (KuzBS).

\section{Materials and Methods}

The work was carried out in 2020 - 2021 in the Kuzbass Botanical Garden (the city of (Kemerovo), located in the northern part of the forest-steppe zone of Western Siberia. The climate of the study area is sharply continental. The average annual air temperature is 0.9 ${ }^{\circ} \mathrm{C}$. The highest air temperature is in summer $\left(35 \ldots 38^{\circ} \mathrm{C}\right)$, the lowest is in winter $\left(-57^{\circ} \mathrm{C}\right)$. The first spring frosts occur from 28 May to 11 June and the first autumn frosts from 26 August to 14 September. The average annual rainfall is $450 \ldots 500 \mathrm{~mm}$. The height of the snow cover is between 47 and $72 \mathrm{~cm}$.

The material for the study is from the collections of the Kuzbass Botanical Garden. The concept of a discrete description of ontogenesis was used for researching the stages of $A$. officinalis ontogenesis under introduction conditions [8,9]. The life form and type of the shoot in the initial stages of ontogenesis is defined by I.G. Serebryakov [10, 11]. The inflorescence is described by T.V. Kuznetsova et al [12].

\section{Results and discussion}

Findings. Individuals' first year of development is divided into three phases: latent, pregenerative, and generative. The stages of ontogenesis are reflected in Fig. 2.
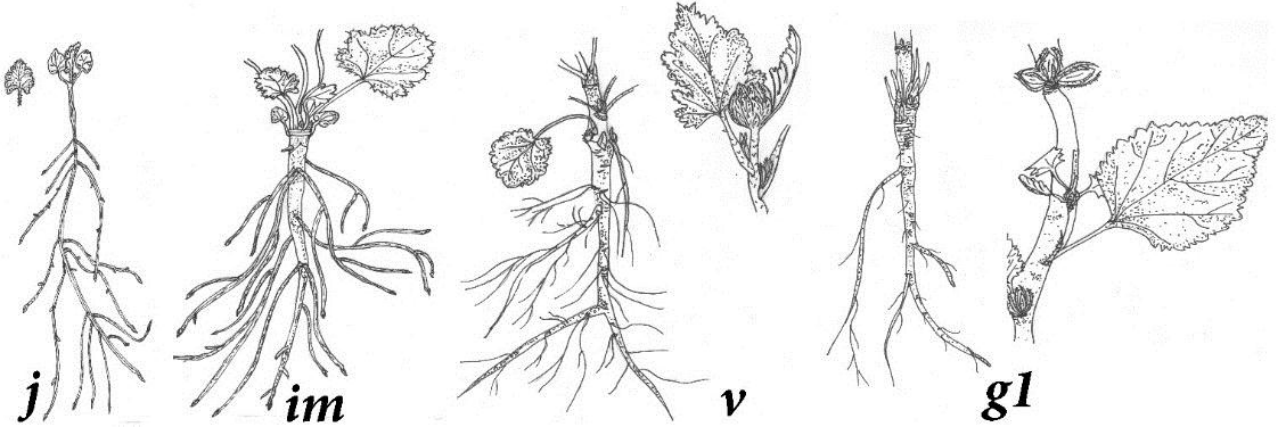

Fig. 2. The initial stages of ontogenesis of Althaea officinalis L. 
Latent period. The seeds are small, 3 to $5 \mathrm{~mm}$ long, bud-shaped, dark brown, glabrous, with hairs appearing on the convex edge of the seed when swollen. Seminal suture is on the concave abdominal part.

The corcule is large and consists of a germinal root, hypocotyl, 2 cotyledons and a bud. Relative to its vertical axis, it is located laterally in the seed. The endosperm is oily, occupying a space of $0.5-1.0 \mathrm{~mm}$ on the concave side (Fig. 3).

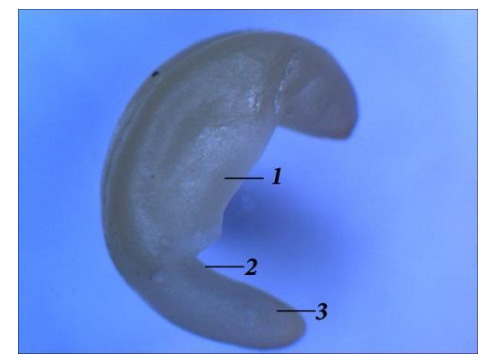

Fig. 3. Corcule of Althaea officinalis: 1. cotyledons; 2. hypocotyl; 3. seminal root.

Seedlings. The seeds germinate $3-5$ days after sowing. The germination rate is $80 \%$. Germination is above ground. Seedlings have two opposite widely ovate cotyledonous leaves $0.5-0.8 \mathrm{~cm}$ long and $0.4-0.6 \mathrm{~cm}$ wide on a short petiole up to $0.4-0.5 \mathrm{~cm}$ long, an open apical bud and the main root. By mid-June, 2 true green leaves develop alternately on the primary rosette shoot. The first couple of leaves is round-shaped, with a serrated edge, pubescent, up to $1.1 \mathrm{~cm}$ long and $1.2 \mathrm{~cm}$ wide, the petiole $0.6-1.2 \mathrm{~cm}$ long. The hypocotyl does not exceed $0.4 \mathrm{~cm}$ in length and $0.2 \mathrm{~cm}$ in diameter and is glabrous. The transition area of the hypocotyl to the main root is well defined. The main root is up to $8 \mathrm{~cm}$ long, $0.1 \mathrm{~cm}$ in diameter, branching out to 2 nd order, forming the main root system. The duration of the ontogenetic stage is $15-20$ days. By this time, the above-ground part of the plants will have reached a height of $2-3 \mathrm{~cm}$.

Juvenile plants. On the primary rosette shoot, up to ten assimilating leaves with narrow-lanceolate, hairy bracts grow. The leaves consistently increase in size. Buds are laid in the axils of the cotyledons and green leaves. The apical bud is covered by the stigmas of the upper rosellate leaves. The shoot height is $8 \mathrm{~cm}$. The leaf lamina is rounded, increasing in size to $2.3 \mathrm{~cm}$ long and up to $3 \mathrm{~cm}$ wide, pubescent in hairs. The root system goes into the soil to a depth of $12 \mathrm{~cm}$. The main root pulls the hypocotyl into the soil and the cotyledon node is on the soil surface. The main root is thickened in a fusiform way, branching out along its entire length up to the second order. The duration of the juvenile stage is on average $15-20$ days.

Immature plants. When immature, the cotyledon leaves die down in early August. The apical meristem splits off 1 long metamer, the shoot becomes semi-rosette and reaches 15 $\mathrm{cm}$ in length. The juvenile leaves are succeeded by adult leaves with pubescent bracts at the base. The leaf is pubescent, up to $6.4 \mathrm{~cm}$ long and $6.6 \mathrm{~cm}$ wide, the petiole is $5.5-7.0 \mathrm{~cm}$ long. The stem is straight, $0.5 \mathrm{~cm}$ in diameter. The main root is $30 \mathrm{~cm}$ long and $0.9 \mathrm{~cm}$ wide. The diameter of the first-order lateral roots in the distal region of the main root increases, while the others remain thin and perform a feeding function.

Virginile plants. The rosellate leaves gradually die off. The shoot grows to $20-30 \mathrm{~cm}$ due to the gradual spreading of the apical bud. 5 - 9 elongate metameres with long-petioled (up to $7.0-9.0 \mathrm{~cm}$ ) green leaves emerge. Their leaf plate has a crenulated edge, pubescent, $7.7 \mathrm{~cm}$ long and $8.0 \mathrm{~cm}$ wide. Vegetative buds are laid in the leaf axils. As the plant grows longer, axillary buds open, creating weakly developed sylleptic vegetative shoots with one small $(0.5-1 \mathrm{~cm})$ ovate leaf with glabrous, narrow-lanceolate leafstalks. The main root is 
up to $35 \mathrm{~cm}$ long, branching out to the 5 th order, thickening together with the first-order lateral roots. The duration of the condition is $10-15$ days.

Young generative plants. The flowering of the marshmallow occurs in the first year of life. The establishment of the reproductive organs in the apical bud determines the plant's transition to the generative stage. Simultaneously with the growth of the orthotropic shoot, lateral generative buds form in the axils of the lower green leaves. The plant blooms at the end of August. By this time it has up to 15 green leaves. They are three-lobed, with a dentate-crenate edge, with a $7.2 \mathrm{~cm}$ long and $6.1 \mathrm{~cm}$ wide base on a short petiole up to $3 \mathrm{~cm}$ long. At the top of the shoot, the shoot ends with an inflorescence, a thyrsus. It is open, bracteous at the top and frondose at the bottom [12], and consists of alternating tiered dichasia. The first flowers $(2-4)$ open in mid-September. The flowers are actinomorphic, ovipotent. Perianth leaves are $1.8 \mathrm{~cm}$ long and $1.5 \mathrm{~cm}$ wide, with a notch on top and scant hairs on the sides. Androecium is multi-pointed. Paracladia, which resemble the main inflorescence in structure, emerge from generative axillary buds in this condition. Synflorescence is a thyrsus brush that has been closed. The basal (rosette) section of the shoot is dragged into the soil by contractile activity of the main and lateral roots in late August/early September. The caudex begins to form. The buds of the upper rosellate leaves grow in size and become regeneration buds, while the remaining buds of the rosellate region of the shoot go dormant. The lateral roots thicken. The main root reaches a length of $48 \mathrm{~cm}$. With the first frost, the elongated generative part of the shoot dies off.

\section{Conclusion}

During the first year of life in the Kuzbass Botanical Garden, individuals of A. officinalis go through five ontogenetic stages: seedling, juvenile, immature, virginile, and young generative. A. officinalis is characterised by the development of a semi-rosette orthotropic monocarpic shoot, branching in a sylleptic way, that flowers in late August/early September. The inflorescence is a multi-stemmed dichasia open thyrsus, and the synflorescence is a thyrsus tassel. The above-ground elongated component of the main shoot dies off towards the end of the growing season, while the rosette with regeneration buds is pushed into the soil by contractile activity of the main and lateral roots and becomes perpetual. The caudex arises when the primary and lateral roots drag the rosette part of the shoot into the soil.

The work was made within the limits of the National task of The Federal Research Center of Coal and Coal Chemistry of Siberian Branch of the Russian Academy of Sciences AAAA-A17117041410053-1 (Project № 0352-2016-0002) «Evaluation of a state and protection of floristic variety affected by anthropogenic and technogenic factors in situ и еx situ». On the base of USS Introduction fund KuzBS № USU 508670

\section{References}

1. M. Palov, Encyclopaedia of Medicinal Plants (1998)

2. G.O. Osmanova, Ontogenetic Atlas of Medicinal Plants (2004)

3. P.S. Chikov, Medicinal Plants (1989)

4. Ali Esmail Al-Snafi, International Journal of PharmTech Research, 5(3):1378-1385 (2013)

5. Ali Shah, Dr Syed \& Naveed, Akhtar \& Akram, Muhammad \& Shah, Pervaiz \& Saeed, Tariq \& Ahmad, Khalil \& Asif, Muhammad. Journal of Medicinal Plant Research. 5, 5662-5666 (2011)

6. Red Book of the Kemerovo Region (2012)

7. Flora of the USSR (1949) 
8. T.A. Rabotnov, Geobotany (1950)

9. I.G. Serebryakov, Morphology of the Vegetative Organs of Higher Plants (1952)

10. W. Die Troll, Infloreszenzen (Jena: Fischer Verlag, 1964)

11. I.G. Serebryakov, Ecological Morphology of Plants (1962)

12. T.V. Kuznetsova, N.I. Pryakhina, G.P. Yakovlev, Inflorescences. Morphological Classification (1992) 